\title{
INHIBITION BY CYANIDE OF DRUG OXIDATIONS IN RAT LIVER MICROSOMES*
}

\author{
Mitsukazu KITADA, Kan CHIBA, Tetsuya KAMATAKI \\ and Haruo KITAGAWA \\ Department of Biochemical Pharmacology, Faculty of Pharmaceutical Sciences, \\ Chiba University, Chiba 280, Japan
}

Accepted February 24, 1977

\begin{abstract}
Cyanide inhibited microsomal activities of aniline hydroxylation and aminopyrine, ethylmorphine and codeine demethylations and produced a modified type II difference spectrum of cytochrome P-450 to give two spectral dissociation constants, $0.21 \mathrm{mM}$ and $1.05 \mathrm{mM}$. The binding of cyanide to cytochrome P-450 resulted in inhibition of NADPH-cytochrome P-450 reductase activity. The cyanide inhibition of drug oxidations was partially avoided by increasing oxygen tension. A possible mechanism for the inhibition of drug oxidations by cyanide is discussed.
\end{abstract}

It has been widely accepted that microsomal activities of drug oxidations are not inhibited by cyanide (1-3). In current views of chemical mechanisms of drug oxidations, microsomal cytochrome P-450 has been established to be the enzyme which catalyzes drug oxidations (4). Since cytochrome P-450 is a heme-protein (5), the inability of cyanide to inhibit drug oixdations seemed to be anomalous. In fact, recent reports have shown that cyanide binds to cytochrome P-450 and produces a characteristic difference spectrum (6, 7). In addition, in contrast to the previous concept, the possibility that cyanide inhibits cytochrome P-450-catalyzed drug oxidations is suggested by several authors in hydroxylation of aniline $(8,9)$ and in cumene hydroperoxide-supported hydroxylation of coumarin (10).

We carried out the present studies in an attempt to determine whether cyanide inhibits drug oxidations.

\section{MATERIALS AND METHODS}

Commercial aniline was redistilled under vacuum and the distillate was stored at about $-10^{\circ}$ under an atmosphere of nitrogen. Other substrates were purchased from commercial sources and used without further purification.

Male Wistar rats weighing 90 to $150 \mathrm{~g}$ were maintained on commercial rat chow, CE2, Nippon Clea Co. Ltd., Japan. The animals were fasted for about $18 \mathrm{hr}$ prior to sacrifice but were given tap water ad libitum. Liver microsomes were prepared as described previously (11). Protein was determined by the method of Lowry et al. (12) using bovine serum albumin as a standard. A typical reaction mixture for drug oxidation assay consisted of

* This work was presented at the 94th Annual Meeting of the Pharmaceutical Socicty of Japan, Sendai, April, 1974 
phosphate buffer $(100 \mathrm{mM}, \mathrm{pH} 7.4), \mathrm{NADP}^{++}(0.33 \mathrm{mM})$, glucose 6-phosphate $(8 \mathrm{mM})$, $\mathrm{MgCl}_{2}(6 \mathrm{mM})$, glucose 6-phosphate dehydrogenase (0.045 unit, EC 1.1.1.49, Boehringer Mannheim, Grade I), EDTA (0.1 mM), microsomes (approx. $1 \mathrm{mg}$ protein) and a substrate $(1 \mathrm{mM})$ in a final volume of $1.0 \mathrm{ml}$. Semicarbazide $(7.5 \mathrm{mM}, \mathrm{pH} 7.0)$ was added for the demethylation assay. When necessary, potassium cyanide was added at concentrations shown in the figures and tables. The reaction mixture was incubated at $37^{\circ}$ for $20 \mathrm{~min}$. Aniline hydroxylation was assayed by determining $p$-aminophenol formed according to the method of Imai et al (13). Oxidative demethylation activities of aminopyrine, cthylmorphine and codeine were measured by determining formaldehyde formed by the method of Nash (14). The drug oxidation activities were calculated from the calibration curve obtained by adding known amounts of $p$-aminophenol or formaldehyde to a similar reaction mixture in order to climinate any possible errors caused by the chemical interference between $p$-aminophenol or formaldehyde and cyanide ion in the incubation mixture. Difference spectrum of cytochrome P-450 was measured essentially by the method described by Schenkman et al. (15) using an Aminco DW-2 recording spectrophotometer. For measuring cyanide-induced difference spectrum of reduced cytochrome P-450, a few $\mathrm{mg}$ of solid dithionite was added in the reference and sample cuvettes just before the measurement, cyanide was then added and the difference spectrum was recorded repeatedly for 20 min. The maximum change of the difference spectrum thus obtained has been used for the calculation of the affinity of cyanide to reduced form of cytochrome P-450. Cytochrome P450 was determined by the method of Omura and Sato (5). NADPH-cytochrome P-450 reductase activity was measured essentially by the method of Dichl et al. (16) using a Hitachi Two Wave Length spectrophotometer, Model 356, in a dual mode. The rate of cytochrome P-450 reduction was calculated using a value of $91 \mathrm{mM}^{-1} \mathrm{~cm}^{-1}$ for the molar extinction increment between $450 \mathrm{~nm}$ and $490 \mathrm{~nm}$.

\section{RESULTS}

Inhibition of drug oxidations by cyanide

To determine whether or not cyanide inhibits drug oxidations, cyanide was added to the reaction mixture containing a definite concentration of a substrate. The results are shown in Table 1. At a concentration of $1.0 \mathrm{mM}$, cyanide inhibited aniline hydroxylation

TABLF. 1. Inhibitory effect of cyanide on microsomal drug oxidations

\begin{tabular}{lcccc}
\hline \multicolumn{1}{c}{ Substrate } & \multicolumn{3}{c}{ Inhibition percent } \\
& $n$ & Activity: & \multicolumn{2}{c}{ KCM (mM) } \\
Aniline $(0.04 \mathrm{mM})$ & 4 & $18.8 \pm 1.5$ & $64.4 \ldots 1.8$ & 73.3 .2 .5 \\
Aminopyrine $(1.0 \mathrm{mM})$ & 2 & $52.0 \pm 11.6$ & $39.4 \pm 4.2$ & $50.5 \pm 0.6$ \\
Codeine $(1.0 \mathrm{mM})$ & 2 & $76.8+15.0$ & $36.6 \pm 0.3$ & $52.4=5.1$ \\
Ethylmorphine $(1.0 \mathrm{mM})$ & 3 & $104.0 \pm 34.1$ & $38.3 \pm 1.7$ & $53.1-4.1$ \\
\hline
\end{tabular}

a) nmole $p$-aminophenol or formaldehyde formed/mg of protein/20 min

Values are mean - SD. 
and aminopyrine, codeine and ethylmorphine demethylations by about $64 \%, 39 \%, 37 \%$ and $38 \%$, respectively.

It has been demonstrated from kinetic results that there are multiple enzymes catalyzing hydroxylation of aniline (17) and demethylation of aminopyrine $(18,19)$. The existence of three species of cytochrome P-450 has also been suggested from the difference in the binding affinity of cyanide to cytochrome P-450 (7). As can be seen in Fig. 1, Dixon plots of aniline hydroxylation vs. cyanide concentrations showed a two phase inhibition. The inhibition constants of cyanide for aniline hydroxylation in lower concentrations and in higher concentrations of cyanide were $0.36 \mathrm{mM}$ and $1.34 \mathrm{mM}$, respectively. Cyanide inhibited aniline hydroxylation non-competitively regardless of cyanide concentrations. Aust and his associates $(18,19)$ reported that there are two $\mathrm{Km}$ values obtainable in the Lineweaver-Burk plots of aminopyrine N-demethylation. The Dixon plots of aminopyrine $\mathrm{N}$ demethylation vs. cyanide concentrations are shown in Fig. 2. Aminopyrine concentrations employed were $0.4 \mathrm{mM}, 0.8 \mathrm{mM}, 1.8 \mathrm{mM}$ and $2.4 \mathrm{mM}$. Interestingly, Dixon plots of aminopyrine $\mathrm{N}$-demethylation showed two inhibition kinetics. In two pairs of substrate concentrations, cyanide inhibited aminopyrine $\mathrm{N}$-demethylation non-competitively. The inhibition constants by cyanide were $2.6 \mathrm{mM}$ and $3.4 \mathrm{mM}$ at ranges of lower and higher concentrations of aminopyrine, respectively. In contrast to the cases with aniline or aminopyrine, only one inhibition constant was obtained in codeine and ethylmorphine demethylations (Figs. 3. 4). The inhibition constants of cyanide in codeine demethylation and ethylmorphine $\mathrm{N}$-demethylation were $1.9 \mathrm{mM}$ and $1.6 \mathrm{mM}$, respectively. As was seen with aniline hydroxylation or aminopyrine $\mathrm{N}$-demethylation, cyanide inhibited codeine and

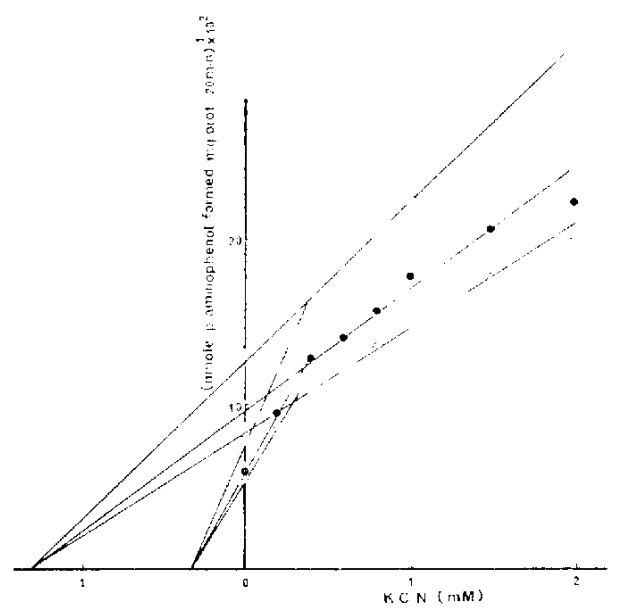

FIC. 1. Cyanide inhibition of aniline hydroxylation in liver microsomes. Experimental condilions are as described in MATFRIALS AND MLTHODS except that concentrations of aniline were 0.02 $\mathrm{mW}(-),. 0.04 \mathrm{mM}(\mathrm{O})$ and 0.06 $\mathrm{mM}(\mathrm{N}-\mathrm{N})$

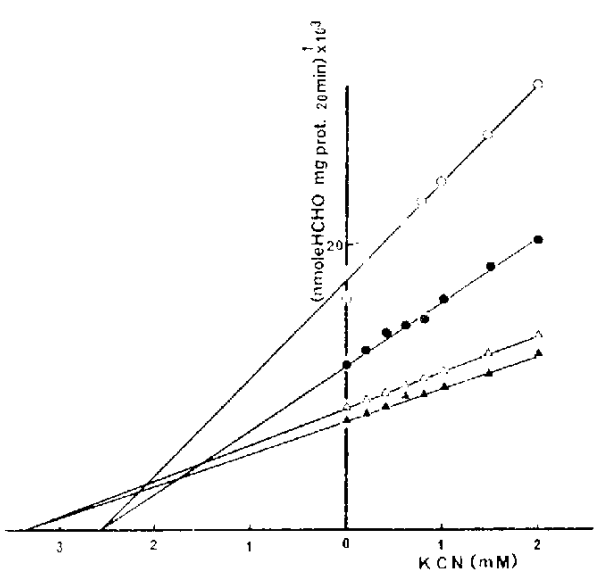

FIG. 2. Cyanide inhibition of aminopyrine $\mathrm{N}$-demethylation in liver microsomes. Experimental details are as described in MAIERIALS AND METHODS except that concentrations of aminopyrine were $0.4 \mathrm{mMl}$ (1-), $0.8 \mathrm{mM}$ (O-O), $1.8 \mathrm{mM}\left(\mathrm{S}^{--}\right)$and $2.4 \mathrm{mM}(\boldsymbol{\Delta}-\boldsymbol{A})$. 


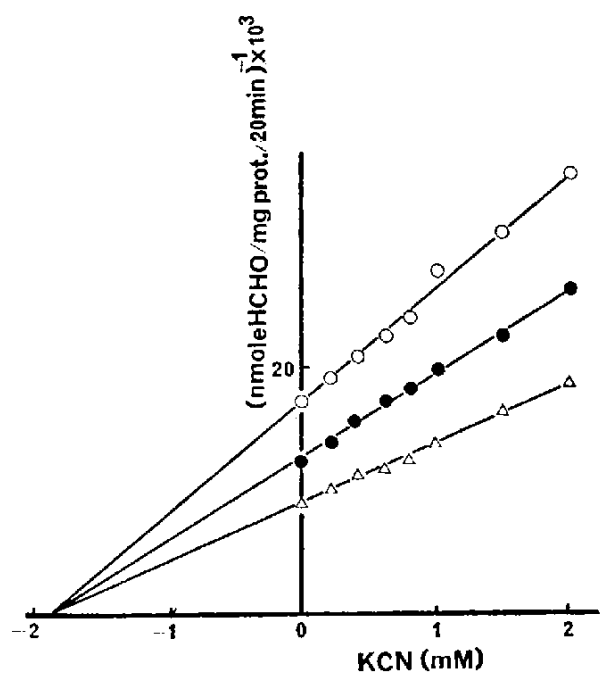

FIG. 3. Cyanide inhibition of codeine demethylation in liver microsomes. Experimental details are as described in MATERIALS AND METHODS section except that concentrations of codeine were $0.1 \mathrm{mM}(-), 0.2 \mathrm{mM}(-\mathbf{0})$ and $0.5 \mathrm{mM}(\Delta-\wedge)$.

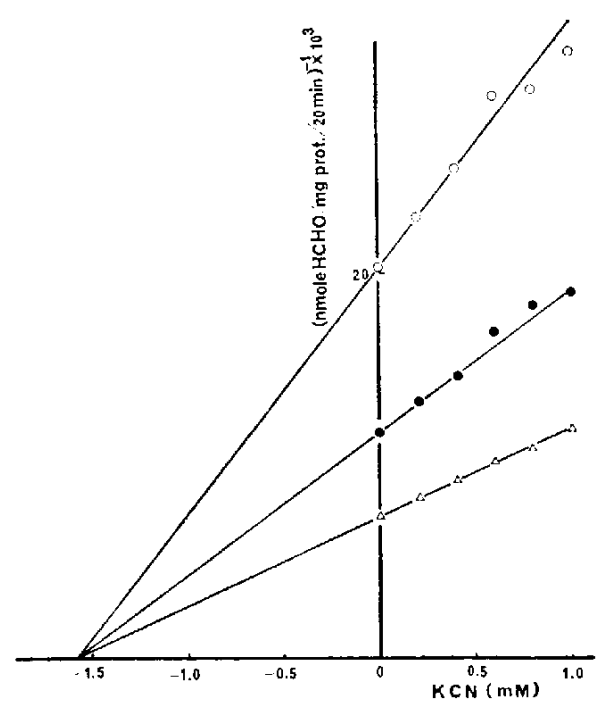

Fig. 4. Cyanide inhibition of ethylmorphine $\mathrm{N}$-demethylation in liver microsomes. Experimental details are as described in MATERIALS AND METHODS section except that concentrations of ethylmorphine were $0.2 \mathrm{mM}(-), 0.4 \mathrm{mM}$ $(-)$ and $0.6 \mathrm{mM}(\triangle-\wedge)$.

ethylmorphine demethylations, non-competitively. Therefore, in all cases in these experiments cyanide inhibited drug oxidations non-competitively.

Cyanide binding to oxidized and reduced forms of cytochrome P-450

To assess possible steps of cyanide inhibition of drug oxidations in the redox cycle of cytochrome P-450, the binding affinity of cyanide to oxidized or reduced form of cytochrome P-450 was measured. Double reciprocal plots of cyanide binding to cytochrome P-450 are shown in Fig. 5. Comai and Gaylor (7) have shown that there were three spectral dissociation constants seen with various concentrations of cyanide. As shown in Fig. 5, we observed two distinguishable spectral dissociation constants depending upon the concentrations of cyanide at a range between $0.1 \mathrm{mM}$ and $2.0 \mathrm{mM}$. The spectral dissociation constants seen in this experiment were $0.21 \mathrm{mM}$ and $1.05 \mathrm{mM}$. The binding affinity of cyanide to a reduced form of cytochrome P-450 is shown in Fig. 6. Double reciprocal plots of cyanide binding to a reduced form of cytochrome P-450 showed a linear curve and the spectral dissociation constant was $6.06 \mathrm{mM}$. Therefore, it can be concluded that cyanide binds to the oxidized form of cytochrome P-450 more firmly than to the reduced form.

Effect of cyanide on cytochrome $P-450$ reduction rate by $\mathrm{NADPH}$

Gigon et al. (20) demonstrated that type II compounds inhibit NADPH-supported reduction rate of cytochrome P-450 whereas such is enhanced by type I compounds. Since it had yet to be established that cyanide inhibits NADPH-dependent cytochrome P-450 


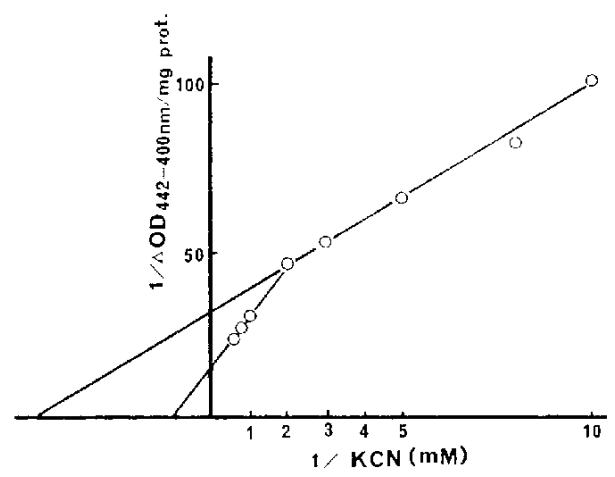

FiG. 5. Double reciprocal plots of cyanide binding to oxidized form of cytochrome P-450. Microsomes $(2.40 \mathrm{mg} / \mathrm{ml})$ were suspended in $0.1 \mathrm{M}$ phosphate buffer, $\mathrm{pH} 7.4$ and the difference spectrum was measured as described in Materials and Methods.

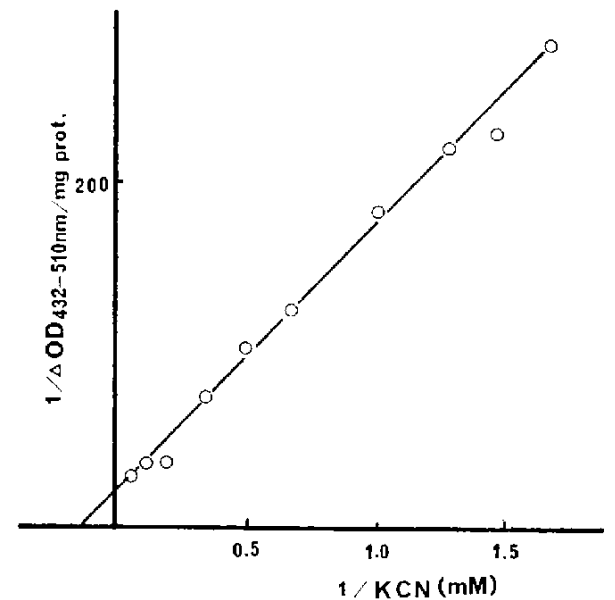

FIG. 6. Doublc reciprocal plots of cyanide binding to dithionite-reduced cytochrome P-450. Microsomes $(1.73 \mathrm{mg} / \mathrm{ml})$ were suspended in $0.1 \mathrm{M}$ phosphate buffer, $\mathrm{pH} 7.4$ and the difference spectrum was measured as described in Materials and Methods.

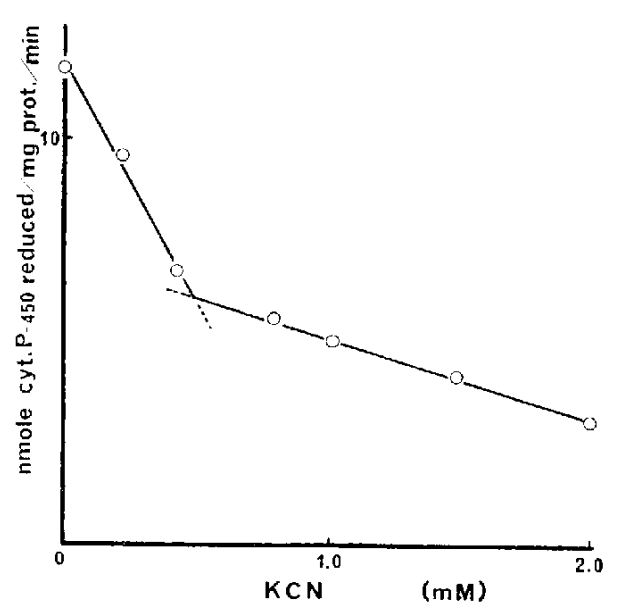

FIG. 7. Effect of cyanide on NADPH-cytochrome $\mathbf{P}-450$ reductase activity. Microsomes $(2.50 \mathrm{mg} / \mathrm{ml})$ were suspended in $0.1 \mathrm{M}$ phosphate buffer, $\mathrm{pH} 7.4$ and NADPH-cytochrome $\mathrm{P}-450$ reductase activity was measured in the presence of various concentrations of cyanide.

reduction, the effect of cyanide on cytochrome $\mathrm{P}-450$ reduction rate was examined. As can be seen in Fig. 7, cyanide inhibited cytochrome P-450 reduction rate and the inhibition was diphasic.

Effects of oxygen tension on cyanide inhibition of drug oxidations

Aniline and cyanide are substrates which bind to the sixth ligand of the cytochrome 
TABLE 2. Effects of oxygen tension on aniline hydroxylation and ethylmorphine $\mathrm{N}$-demethylation in the presence and absence of potassium cyanide

\begin{tabular}{ccccc}
\hline Oxygen & \multicolumn{2}{c}{ Aniline hydroxylation } & \multicolumn{2}{c}{ Ethylmorphine N-demethylation } \\
$(0)$ & $\mathrm{K}(\mathrm{N}$ & $\mathrm{K}(\mathrm{V}(0.25 \mathrm{miv})$ & $\mathrm{KCN}$ & $\mathrm{KCN}(0.25 \mathrm{mM})$ \\
2.5 & 18.55 & $9.42(50.8)^{\prime}$ & $57.6(1$ & $43.72(75.8)$ \\
5 & 18.67 & $1(133(55.3)$ & 75.96 & $58.29(76.7)$ \\
10 & 19.52 & $11.13(57.0)$ & 71.18 & $54.08(76.0)$ \\
20 & 19.88 & $11.43(57.5)$ & 73.17 & $58.29(79.7)$ \\
40 & 19.52 & $12.72(65.2)$ & 62.14 & $49.53(79.8)$ \\
100 & 19.09 & $14.18(74.2)$ & 54.88 & $53.10(96.8)$ \\
\hline
\end{tabular}

Experimentat details are as described in Materials and Methods except that aniline concentration in the reaction mixture was $0.1 \mathrm{mM}$. a) nmole p-aminophenol formed/mg of protein $20 \mathrm{~min}$; b) nmole formaldelyde formed/mg of protein $20 \mathrm{~min}$; c) percent of the activity toward corresponding control activily.

P-450 heme and produce type II binding spectrum (15). Since cyanide inhibited aniline hydroxylation non-competitively, it might be reasonable that the active site(s) of cytochrome P-450 for aniline hydroxylation is located in the protein moicty rather than in the heme moiety of cytochrome P-450 molecule. In another words, the type II difference spectrum of cytochrome P-450 induced by aniline would not correlate with aniline hydroxylation. In fact, Schenkman et al. (15) demonstrated that spectral disseciation constant (Ks) obtained from type II difference spectrum of cytochrome P-450 induced by aniline is much greater than Michaelis constant $(\mathrm{Km})$ for aniline hydroxylation. Cytochrome P-450 also functions as an oxygen activator for oxidation of drugs and other substrates. Since oxygen is thought to bind to the sixth ligand of the cytochrome P-450 heme, it is feasible that cyanide inhibition of drug oixdations would be affected by oxygen tension. As can be seen in Table 2, cyanide inhibition of aniline hydroxylation and ethylmorphine $\mathrm{N}$-demethylation was partially reversed with increasing the oxygen tension.

\section{DISCUSSION}

Matsubara and Tochino (8) reported that inhibitory patterns of aniline hydroxylases observed at lower and higher concentrations of cyanide were non-compctitive and competitive, respectively. In the present study, we found that at lower and higher concentrattions, cyanide inhibited drug oxidations including aniline hydroxylation non-competitively. As will be reported elsewhere, we found that the use of high concentrations of cyanide together with higher concentrations of aniline enhances aniline hydroxylation. Consequently, when $1 \mathrm{mM}$ rather than $0.04 \mathrm{mM}$ aniline was added to the incubation mixture, aniline hydroxylation was inhibited to a lesser degree. Therefore, differences in the inhibition patterns of aniline hydroxylation by cyanide between these two studies are due to the difference of aniline concentrations. In addition, this finding led us 10 use $0.04 \mathrm{mM}$ rather than $1.0 \mathrm{mM}$ aniline in the experiment shown in Table 1. As regards mechanisms of cyanide inhibition, our recent studies indicated that the inhibition by cyanide of cumene hydroperoxide-supported aniline hydroxylation was weaker than that of NADPH-supported 
aniline hydroxylation, that the inhibition by cyanide of cumene hydroperoxide-supported aniline hydroxylation was not reversed by high oxygen tension, and that cyanide binding to oxidized form of cytochrome P-450 was not changed by oxygen tension (not shown). These results parly support the idea that cyanide inhibition is not due to the competition between cyanide and aniline for a binding site of oxidized form of eytochrome P-450.

Schenkman et al. (15) demonstrated that there was a great difference between $K s$ and $\mathrm{K} m$ values for aniline. This great difierence was also noted by several authors including Matsubara and Tochino (9). However, Matsubara and Tochino accounted for the mechanism of cyanide inhibition of aniline hydroxylation by means of spectral interference between aniline and cyanide using microsomes which contained an oxidized form of cytochrome P-450. Since the significance of the type II binding of aniline to cytochrome P450 has yet to be established, the mechanism proposed for cyanide inhibition of aniline hydroxylation (9) may be challenged.

It has been widely accepted that the cytochrome P-450-substrate complex receives first electrons from NADPH-cytochrome P-450 reductase, and then binds to molecular oxygen to form an oxygenated form of cytochrome P-450-substrate complex which is spectrophotometrically detectable $(21,22)$. Inai and Sato $(23,24)$ discussed the inhibition mechanism of ethylisocyanide on aniline hydroxylation and suggested that ethylisocyanide reduces binding affinity of cytochrome P-450 to molecular oxygen. Because of the spectral interference between cyanide-cytochrome P-450 (in its reduced or oxidized form) complex and oxygenated form of cylochrome P-450 at about $440 \mathrm{~nm}$, it is almost impossible to determine the exact rate of formation of oxygenated form of cytochrome P-450 in the presence of cyanide. However, our preliminary studies showed that cyanide inhibits the formation of oxygenated form of cytochrome P-450 induced by ethylmorphine. The affinity of the reduced form of cytochrome P-450 to molecular oxygen is reported to be $0.13{ }^{\prime \prime} \mathrm{M}$ (24). Thus binding affinity of the reduced form of cytochrome P-450 to cyanide $(6.06 \mathrm{mM})$ is much lower than that to molecular oxygen. Therefore, it seems most likcly that cyanide binding to the reduced form of cytochrome P-450 causes a modification of cytochrome P-450 molecules and reduces the atfinity of cytochrome P-450 10 molecular oxygen. The data shown in Fig. 7 indicate that cyanide inhibits cytochrome P-450 reduction rate. To climinate the possibility that cyanide inhibits carbon monoxide binding to the reduced form of cytochrome P-450, the interference of cyanide with carbon monoxide was examined. The presence of $2.0 \mathrm{mM}$ cyanide inhibited carbon monoxide binding to dithionite-reduced cytochrome P-450 by only $9.8 \%$ (data not shown). The greater decrease in NADPHcytochrome P-450 reduction rate does not therefore appear to be due to the competition between cyanide and carbon monoxide to the reduced form of cylochrome P-450. Although cyanide inhibited the NADPH-cytochrome $\mathrm{P}-450$ reduction rate, the inhibition of cytochrome P-450 reduction rate does not appear to be the cause of inhibition of drug oxidations by cyanide, since the cyanide inhibition of drug oxidations was reversed by high oxygen tension; the introduction of oxygen to the reduced form of cytochrome P-450 is the rate limiting step in the over all drug hydroxylation reaction in the presence of cyanide. 


\section{REFERENCES}

1) Cooplr, D.Y. And Brodi, B.B.: J. Pharmacol. exp. Ther, 114, 409 (1955)

2) La Du, B.N., Gaudette, L., Trousof, N. A.vd Brodie, B.B.: J. biol. Chem. 214, 741 (1955)

3) Grllette, J.R., Brodie, B.B. ANd LA DL, B.N.: J. Phamacol. exp. Ther. 119, 532 (1957)

4) Cooper, D.Y., Llyin, S., Narasimhulu, S., Rosenthal, O. and Estabrook, R.W.: Science $147,400(1965)$

5) OMlira, T. AND SAlo, R.: J. biol. Chem. 239, 2370 (1964)

6) Shimakata, T., Mhara, K. and Sato, R.: Biochem. biophys. Res. Commun, 44, 533 (1971)

7) Comai, K. and Gaylor, J.L.: J. biol. Chem. 248, 4947 (1973)

8) Matsubara, T. and TochiNo, Y.: FEBS Letters 52, 77 (1975)

9) Matsubara, T. And Tochino, Y.: Archs Biochem. Biophys. 172, 696 (1976)

10) Raimitlla, A.D. and O’Brilin, P.J.: Biochem. biophys. Res. Commun. 60, 440 (1974)

11) Kamatakl, T. anid Kiragawa, H. : Japan. J. Pharmacol. 24, 195 (1974)

12) I.owry, O.H., Rosebrough, N.J., Farr, A.L. And Randall, R.J.: I. biol. Chom. 193, 265 (1951)

13) Imai, Y., Ito, A. And Sato, R.: J. Biochem., Tokyo 60, 417 (1966)

14) NasH, T.: Biochem. I. 55, 416 (1953)

15) Schenkman, J.B., Remmer, H. and Estabrook, R.W.: Mol. Pharmacol. 3, 113 (1967)

16) Difhl, H., Schadeln, J. And Ullrich, V.: Hoppe-Seyler's Z. physiol. Chem. 351, 1359 (1970)

17) Wada, F., Simmakawa, H., Takasugl, M., Kotake, T. and Sakamoio, Y.: J. Biochem., Tokyo 64, $109(1968)$

18) Pidfron, T.C. And Alst, S.D.: Biochem. Pharmacol, 19, 2221 (1970)

19) Aust, S.D. And Strvfns, J.B.: Biochem. Pharmacol. 20, 1061 (197!)

20) Gigon, P.L., Gram, T.E. and Gilemte, J.R. : Biochem. biophys. Res. Commun. 31,558 (1968)

21) Hildebrandt, A. And Estabrook, R.W.: Archi Biochem. Biophys. 143, 66 (1971)

22) Estabrook, R.W., Hildibranist, A.G., Baron, J., Netter, K.J. and Lfibman, K.: Biochem. bioplys. Res. Conmun. 42, 132 (1971)

23) IMAi, Y. AND SATO, R.: Biochom. hiophys. Res. Commun. 25, 80 (1966)

24) IMAI, Y. AND SATO, R.: J. Biochem. Tokfo 63, 380 (1968) 